\title{
Influence of Pre-Fire Tree Mortality on Fire Severity in Conifer Forests of the San Bernardino Mountains, California
}

\author{
Monica L. Bond ${ }^{*}, 1$, Derek E. Lee ${ }^{2}$, Curtis M. Bradley ${ }^{3}$ and Chad T. Hanson ${ }^{4}$ \\ ${ }^{1}$ P.O. Box 151172, San Rafael, CA 94915, USA \\ ${ }^{2}$ PRBO Conservation Science, 3820 Cypress Drive \# 11, Petaluma, CA 94954, USA \\ ${ }^{3}$ Center for Biological Diversity, P.O. Box 1178, Flagstaff, AZ, 86002, USA \\ ${ }^{4}$ Department of Plant Sciences, University of California, Davis, CA 95616, USA
}

\begin{abstract}
High tree mortality due to drought and insects often is assumed to increase fire severity once ignition occurs. In 2002-2003, coniferous forests in the San Bernardino Mountains, California experienced a significant tree mortality event due to drought and an outbreak of western pine beetles (Dendroctonus brevicomis). In October 2003, fire burned approximately 5,860 ha of conifer forest types in many beetle- and drought-affected stands where most pre-fire dead trees had retained needles. We used pre- and post-fire GIS data to examine how fire severity was affected by pre-fire tree mortality, vegetation characteristics, and topography. We found no evidence that pre-fire tree mortality influenced fire severity. These results indicate that widespread removal of dead trees may not effectively reduce higher-severity fire in southern California's conifer forests. We found that sample locations dominated by the largest size class of trees $(\geq 61 \mathrm{~cm}$ diameter at breast height (dbh)) burned at lower severities than locations dominated by trees $28-60 \mathrm{~cm}$ dbh. This result suggests that harvesting larger-sized trees for fire-severity reduction purposes is likely to be ineffective and possibly counter-productive.
\end{abstract}

\section{INTRODUCTION}

Tree mortality due to drought and insect attacks is common in western coniferous forests [1], but may be increasing in recent years in some areas [2,3]. Bark beetles (Coleoptera: Scolytidae) are common native insects that kill firs and pines, and are capable of large-scale population increases following disturbances such as droughts $[4,5]$. Dense forests are considered relatively more susceptible to insect mortality [6, 7], and recent studies have concentrated on how prescribed fire and thinning affect susceptibility of trees to insects $[5,8,9]$. However, few data are available on the influence of tree mortality on fire behavior.

Stands with high tree mortality due to drought and insects often are presumed to burn at higher severity during fires, increasing the mortality of dominant overstory vegetation in the stand $[10,11]$. This assumption is based on expectations of greater dead fine and coarse fuel loads, including canopy fuels, resulting from pre-fire mortality [11]. The hypothesis that insect-caused tree mortality increases fire severity has relied upon two principal assumptions: (1) dead needles remaining on trees could increase the amount and vertical continuity of fine, dry fuels $[11,12]$; and (2) tree mortality could open the canopy and intensify seasonal desiccation of understory fuels [12]. However, the few empirical studies testing this hypothesis have not found support for it. A widespread low-severity fire in subalpine forest in the White River National Forest, Colorado did not burn any stands

*Address correspondence to this author at the P.O. Box 151172, San Rafael, CA 94915, USA; Tel: +1 415 630-3488; E-mail: monibond@gmail.com affected by spruce beetle (Dendroctonus rufipennis) outbreaks that occurred several decades prior to the fire [13]. Furthermore, a regional analysis of 303 fires in the White River National Forest found that beetle-affected stands did not burn at higher severities than unaffected stands in fires occurring several decades after the outbreak [12].

The hypothesis that stands with recent high tree mortality due to drought or insects have an elevated probability of burning at higher severity when a fire occurs has never been empirically tested. We examined whether fire severity in two large fires that occurred in the midst of a tree mortality event was influenced by the number of trees killed by drought and insects. Specifically, we investigated whether pre-fire tree mortality increased fire severity in stands after ignition occurred. We did not examine the probability of fire igniting in a stand over broad spatial and temporal scales [e.g., 12, 14].

Beginning in rainfall year 1998-1999, southern California entered a period of major drought and higher temperatures. In 2000, the San Bernardino National Forest began to document unusually high mortality of incense-cedars (Calocedrus decurrens), and in 2001 slightly increased mortality was witnessed in ponderosa (Pinus ponderosa), Coulter ( $P$. coulteri) and Jeffrey ( $P$. jeffreyi) pines (L. Merrill, USDA Forest Service, unpublished data 2003). ${ }^{1}$ In 2002, an outbreak of western pine beetles (D. brevicomis)

\footnotetext{
${ }^{1}$ Merrill L. Bark beetles and tree mortality in the San Bernardino Mountains: Current situation and outlook. USDA Forest Service, Region 5 , Southern California Shared Service Area. Unpublished Report, June 24, 2003.
} 
resulted in what the USDA Forest Service identified as 'above background' mortality levels of ponderosa and Coulter pines, and many other conifer tree species were dying from drought alone (L. Merrill, USDA Forest Service, unpublished data 2003). In the first half of 2003, both western pine beetles and mountain pine beetles $(D$. ponderosae) were actively colonizing and killing thousands of conifer trees. By April 2003, the San Bernardino National Forest had mapped approximately 70,000 ha with elevated levels of conifer mortality (L. Merrill, USDA Forest Service, unpublished data 2003).

In late October 2003, one year after the beginning of the beetle population outbreak, two large human-ignited fires merged together in the San Bernardino Mountains and burned 5,863 ha of conifer and conifer-hardwood forest types, including stands with high levels of tree mortality due to drought and insects (Fig. 1). The Old and Grand-Prix fires were driven by hot Santa Ana winds which typically sweep through southern California during the fall [15]. No widespread harvest of the beetle- and drought-killed trees had occurred at the time of the fires.

\section{MATERIALS AND METHODOLOGY}

We selected the San Bernardino Mountains study area because of the existence of Geographic Information System (GIS) layers depicting structural characteristics of vegetation, topography, pre-fire tree mortality immediately prior to the fires, and fire severity, allowing us to investigate the influence of numbers of recently dead trees on fire severity. We simultaneously investigated the effects of topography (slope and aspect), tree size, and canopy cover on fire severity in burned stands, because these factors also are known to influence fire behavior $[16,17]$.

Conifer forests in the San Bernardino Mountains consist of mixed-evergreen forests [18] below $1,500 \mathrm{~m}$, and ponderosa pine, Jeffrey pine, Coulter pine, white fir (Abies concolor)-sugar pine ( $P$. lambertiana), and bigcone Douglas-fir (Pseudotsuga macrocarpa) stands above 1,500 $\mathrm{m}[19,20]$. Various combinations of white fir, Jeffrey pine, ponderosa pine, Coulter pine, sugar pine, incense-cedar, and black oak (Quercus kelloggii) occur at higher elevations, and canyon live oak ( $Q$. chrysolepis) and bigcone Douglas-fir

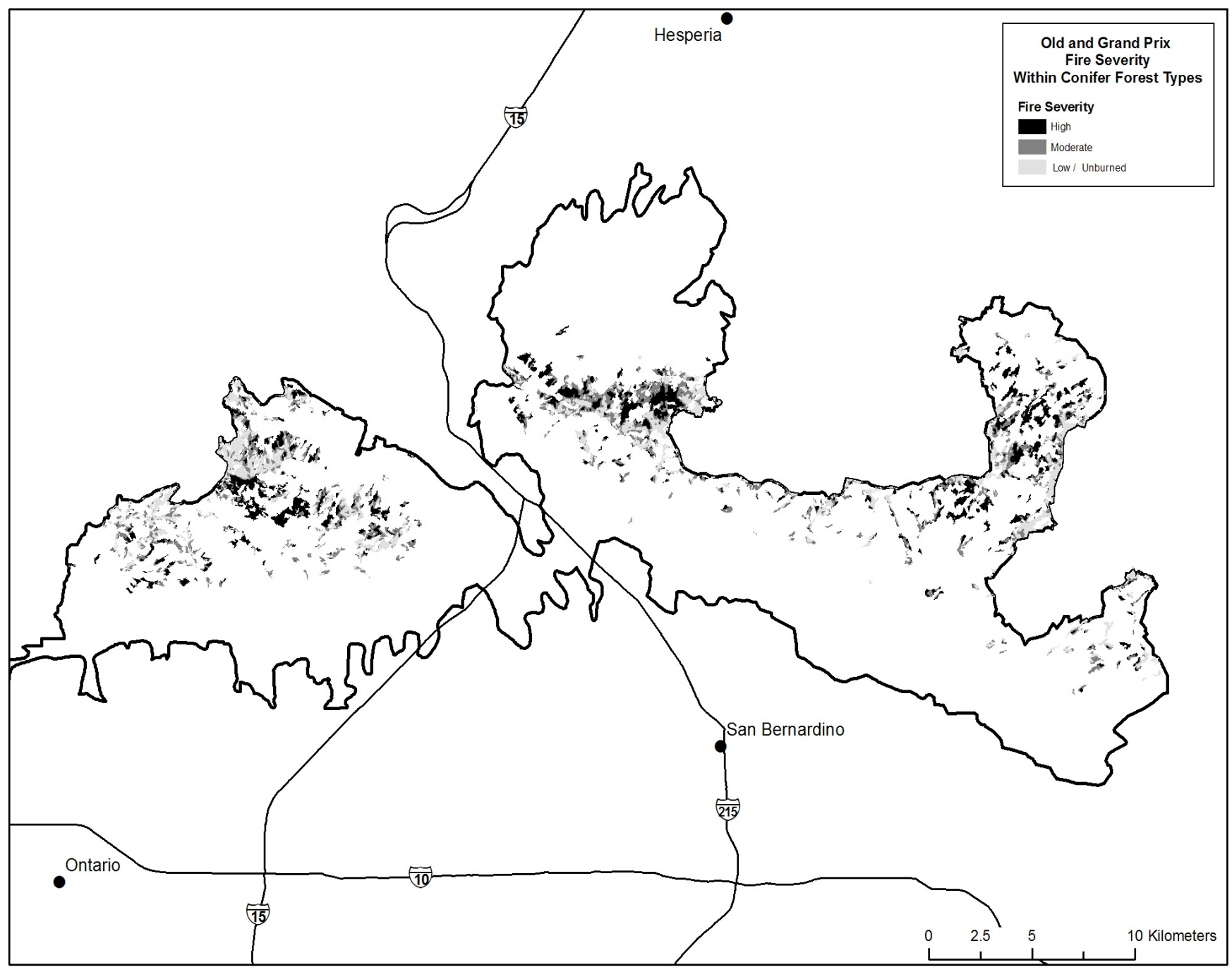

Fig. (1). Perimeters of the 2003 Old and Grand-Prix fires and RdNBR fire severity (low/unburned, moderate, moderate/high) within conifer forest types (Jeffrey Pine, Sierra Mixed Conifer, Montane Hardwood-Conifer). White areas within the fire perimeter are non-conifer vegetation. 
dominate at lower elevations [21]. Historic fire return intervals in these forests were variable, with some forest types exhibiting relatively longer fire-free intervals associated with mixed-severity fire effects [20].

We acquired GIS data on vegetation type and structure [22] and pre-fire tree mortality [23] from the USDA Forest Service and GIS data on fire severity [24] and topography [25] from the US Geological Survey. The detailed methodology used by the agencies to create these GIS maps was explained in the metadata for the layers, and is summarized here. Our variables of interest were vegetation type, size of dominant trees, canopy cover, slope, aspect, number of dead trees per ha prior to the fire, and fire severity.

Vegetation type, size class of dominant trees, and canopy cover were derived from a map of existing vegetation from 2002-2003 (EVEG Tiles) [22]. The vegetation layer was generated using a combination of automated systematic procedures, remote-sensing classification, and photo editing and ground surveys to reduce bias while mapping large areas. Minimum mapping size for contrasting vegetation conditions based on cover type, vegetation type, tree cover, and diameter class was 1 ha and pixel size was $30 \mathrm{~m}$.

Cover types were delineated using Landsat Thematic Mapper imagery into the following broad classes: (1) Conifer $=>10 \%$ conifer cover as dominant type; (2) Mix = $>10 \%$ tree cover and $20-90 \%$ hardwood cover; (3) Hardwood $=>10 \%$ hardwood cover as dominant type; (4) Shrub $=>10 \%$ shrub cover as dominant type; (5) Grass $=$ $>10 \%$ grass cover as dominant type; (6) Barren $=<10 \%$ cover of any natural vegetation; (7) Agriculture; (8) Urban; and (9) Ice/snow. Attributes including tree cover from above and overstory tree diameter interpreted from aerial photography and satellite imagery were then mapped within the cover type classes and used to develop additional classifications. We used California Wildlife Habitat Relations (WHR) [26] to describe specific vegetation types, canopy cover, and tree size-class. "WHR vegetation type," is derived primarily from CALVEG cover type and relative cover of conifer and hardwood trees for mixed vegetation types. For our study area, the WHR vegetation types consisted of Jeffrey Pine, Sierra Mixed Conifer, Montane Hardwood-Conifer, Eastside Pine, and Closed-cone PineCypress. "WHR density" is a measure of tree density indexed by percent canopy cover and included: Sparse (10.0-24.9\%), Poor (25.0-39.9\%), Moderate (40.0-59.9\%), and Dense $(\geq 60 \%)$. "WHR size" identified size classes of overstory trees. WHR size included the following three classes: WHR size $3=$ dominated by trees $15-27 \mathrm{~cm}$ dbh; WHR size $4=$ dominated by trees $28-60 \mathrm{~cm}$ dbh; WHR size $5=$ dominated by trees $\geq 61 \mathrm{~cm} \mathrm{dbh}$.

The GIS layer depicting tree mortality was created from annual aerial surveys conducted by the USDA Forest Service. Current-year tree mortality from 2001-2003 was sketch-mapped by an aerial observer who quantified the number of yellow to reddish brown trees. Polygons were categorized by mortality type (drought or insect kill) and number of trees affected per acre (we converted acres to hectares for this study). Generally, areas with $<1$ tree per acre of mortality were considered to have background levels of mortality and were not usually mapped during the flight.
The resulting layer is a vector data set of polygons each associated with a level of tree mortality for that year. Each year's layer was non-cumulative with respect to numbers of dead trees; however, we used only the 2003 GIS map in our analyses because (1) prior to 2003, few polygons showed above-background levels of mortality within the fire perimeter and (2) we were interested only in very recent mortality since these trees were most likely to have retained dead needles to potentially contribute to fire severity. Therefore, the actual number of all dead trees in a given polygon was likely higher than reported herein.

The fire severity GIS data of the 2003 Old and Grand Prix fires were derived from Landsat Thematic Mapper data. Pre-fire and post-fire data were used to create a Relative delta Normalized Burn Ratio (RdNBR) image, which portrays fire severity to vegetation within a fire while accounting for variation in pre-fire live tree cover, as described in Miller and Thode [27]. Because we were interested in ascertaining whether pre-fire tree mortality influenced fire severity, we used a relative rather than absolute index. Absolute dNBR measures how much vegetation was killed by the fire, while RdNBR measures the amount of vegetation killed in relation to the amount of prefire vegetation [27]. Miller and Thode [27] found that RdNBR more accurately classified high-severity fire effects than dNBR in heterogeneous landscapes with variable amounts of pre-fire vegetation, such as our study area in the San Bernardino Mountains. Higher RdNBR values are correlated with more severe burning of vegetation. The RdNBR image was classified into 4 classes of fire severity based on cutoff thresholds informed by field data collected on understory, midstory, and overstory vegetation one year post-fire on several fires from 2001 through 2004 using Composite Burn Index (CBI) protocols [27]. We used CBI classifications because they provide information about fire effects on all vegetation strata from the forest floor to the upper canopy, and are a useful and easily understood measurement for managers.

The fire severity map identified 4 classes of fire severity. "Unchanged" included areas in which conditions one year after the fire were indistinguishable from pre-fire conditions. "Low Severity" represented areas of surface fire with little change in cover and little mortality of the dominant vegetation. "Moderate Severity" was between low and high and represented a mixture of effects on the dominant vegetation. "High Severity" represented areas where the dominant vegetation had high to complete mortality of canopy foliage due to the fire. We used this classification system to represent the severity of fire in the forest canopy in our analyses. For areas mapped as high severity using RdNBR, we categorized these as "moderate/high severity" because RdNBR measures fire-induced mortality of canopy foliage, rather than tree mortality. The RdNBR high-severity mapping category has a lower threshold of $80 \%$ canopy mortality, which equates to $65 \%$ tree mortality for trees $>20$ $\mathrm{cm}$ dbh [28]. Basal area mortality would likely be somewhat lower than $65 \%$, since the larger trees that dominate in terms of basal area are less fire-susceptible than the abundant small trees that dominate in terms of tree density [29].

The GIS layers of vegetation type and structure, pre-fire tree mortality, and a Digital Elevation Model [25] were 
clipped to the Old and Grand Prix fire perimeters. We selected conifer and mixed hardwood-conifer type polygons from within the vegetation layer for analyses. We generated 500 randomly located points throughout the conifer and mixed hardwood-conifer forest types to create a table of sample stand locations. At each sample location we determined the values of the variables: (1) slope [\%]; (2) aspect [degrees]; (3) mortality [drought and beetle killed only] expressed as the number of dead trees per ha from year 2003; (4) WHR vegetation type; (5) WHR size; (6) WHR density; and (7) fire severity.

We removed 31 locations from our sample due to small sample sizes within specific categories, including: (1) the 5 locations where $W H R$ size $=3$; (2) 8 locations of various WHR vegetation types that had $<5$ samples in categories; and (3) 18 locations in the Closed-Cone Pine-Cypress type. Final sample size was 469 random points in WHR types Jeffrey Pine, Sierra Mixed Conifer, and Montane Hardwood-Conifer (hereafter conifer forest), in WHR size classes 4 and 5. WHR densities were modified from categorical variables to the mean value of each category $(17.5 \%, 32.5 \%, 50 \%$, and $80 \%$ ). Pre-fire tree mortality data was expressed in terms of total number of dead trees per ha in 2003 (immediately prior to the October fires).

We analyzed how fire severity was affected by pre-fire insect and drought mortality along with topography, tree size, and canopy cover variables using two model structures best suited to categorical response variables: binomial and rank-ordered logistic. For the binomial method, we created a generalized linear model (GLM) using a binomial error structure and a logit link function to examine the effects of explanatory variables on the probability that each randomly selected location experienced moderate/high severity fire. The binomial response variable was moderate/high severity burn $=1$; and unchanged, low, or moderate severity burn $=0$. For the rank-ordered method we performed ordered logistic regression (OLR) to fit an ordered logit model examining how explanatory variables affected the probability that each randomly selected location burned at low, moderate, or moderate/high severity. Our response variable, fire severity, was treated as ordinal under the assumption that the levels of fire severity have a natural ordering (low to moderate/high), but the distances between adjacent levels are unspecified. All analyses were performed using Stata 8.2 (Stata Corp. 2004, College Station, Texas 77845).

We generated binomial categorical variables for aspect (south, east, and west), WHR type (Sierra Mixed Conifer and Montane Hardwood-Conifer), and WHR size 5, conditioning the model on north-facing slopes of Jeffrey Pine dominated by trees 28-60 cm dbh (WHR size 4). WHR density was included to control for variation in stand density (canopy cover) within mortality polygons and across the landscape. Slope, aspect, WHR size, and WHR vegetation type variables were included because all of these factors can influence fire behavior $[16,17]$.

We used trend surface analysis to model broadscale spatial pattern in the burn-severity data as a control for spatial autocorrelation. This methodology has two primary aims [30, 31]: (1) to guard against false correlations between fire severity and explanatory variables, as may arise when an unmeasured environmental factor causes a common spatial structure in fire severity and in the measured explanatory variables; and (2) to determine if there is a substantial amount of broadscale spatially structured variation in the fire-severity data that is unexplained by the measured explanatory variables. We fitted a trend surface to fire severity by including variables for $x$ and $y$ spatial coordinates of each sample location, polynomial terms up to the thirddegree, and interactions. Prior to analysis, $x$ and $y$ were centered on their respective means to reduce collinearity with higher-order terms [31] and standardized to unit variance. Nonsignificant $(P>0.05)$ trend surface terms were removed by stepwise selection.

\section{RESULTS}

Fire severity in the Old and Grand Prix fires was highly variable, as is typical of forest fires, leaving patches of unburned and lightly burned areas intermixed with moderate and moderate/high severity patches (Fig. 1). Throughout conifer forest, the fires burned 1,882 ha (32\%) at moderate/high severity; 2,010 ha (34\%) at moderate severity; 1,385 ha $(24 \%)$ at low severity; and 586 ha $(10 \%)$ remained unchanged. The distribution of fire severity categories of our sample locations closely matched the distribution of fire severities in conifer forest throughout the study area $(32 \%$ at moderate/high severity; $34 \%$ at moderate severity; $23 \%$ at low severity; and $12 \%$ remained unchanged). Tree mortality due to drought and beetle infestation prior to the fire ranged from an average of 0 to 21.83 dead trees per ha in each polygon. In smaller patches within a polygon the density of dead trees may have been much higher. Fifty percent of our sample locations had no pre-fire tree mortality above background level. Of the remaining $50 \%$ of our sample locations with above-background tree mortality levels, most observations were evenly distributed among four categories: (1) $<2.47$; (2) 7.41-12.35; (3) 14.83 ; and (4) $19.77-22.24$ dead trees per ha. The original data were reported in these categories and were expressed in terms of dead trees per acre. We converted acres to hectares to derive our dead tree density values.

The GLM indicated that pre-fire tree mortality due to drought and beetle infestation did not significantly affect the probability that a location within the fire burned at moderate/high severity $(P=0.88$; Table 1$)$, while controlling for the effects of topography and vegetation characteristics. Burned locations in Montane Hardwood-Conifer vegetation were significantly more likely $(P=0.04)$ to burn at moderate/high severity than locations in Sierra Mixed Conifer or Jeffrey Pine vegetation. Western aspect decreased the probability of moderate/high severity fire $(P<0.10$; Table 1). The pseudo $r^{2}$ value was 0.067 , indicating that $7 \%$ of the variation in probability of high-severity fire was explained by our model.

Similarly, the OLR indicated that pre-fire tree mortality did not increase the probability that a location within the fire area burned at higher severity $(P=0.53$; Table 2). Montane Hardwood-Conifer vegetation significantly increased the probability that a location burned at higher severity than Sierra Mixed Conifer or Jeffrey Pine vegetation $(P<0.001$; Table 2). Sample locations with western aspect and those dominated by trees $\geq 61 \mathrm{~cm}$ dbh were more likely $(P<0.10)$ to burn at lower severities relative to locations with north 
Table 1. Table of Coefficients from a Binomial Generalized Linear Model (GLM) Examining Effects of Pre-fire Tree Mortality, Slope, Aspect, Vegetation Type, Tree Size Class, and Canopy Cover Class on Probability of Moderate/High Severity Fire in Conifer Types within the October 2003 Old and Grand Prix Fires in the San Bernardino National Forest, California (n =469).

\begin{tabular}{|c|c|c|c|c|c|c|}
\hline Variable & Coeff. & SE & $\mathbf{z}$ & $\mathbf{P}>|\mathbf{z}|$ & \multicolumn{2}{|c|}{$95 \%$ CI } \\
\hline Insect/drought mortality & 0.005 & 0.035 & 0.15 & 0.882 & -0.064 & 0.074 \\
\hline East & -0.062 & 0.263 & -0.24 & 0.812 & -0.577 & 0.452 \\
\hline South & -0.293 & 0.345 & -0.85 & 0.395 & -0.970 & 0.383 \\
\hline WHR size 5 & -0.361 & 0.228 & -1.58 & 0.114 & -0.808 & 0.087 \\
\hline WHR type MHC * & 0.575 & 0.283 & 2.03 & 0.043 & 0.019 & 1.130 \\
\hline WHR type SMC & -0.637 & 0.698 & -0.91 & 0.362 & -2.004 & 0.731 \\
\hline WHR density & 0.011 & 0.007 & 1.55 & 0.120 & -0.003 & 0.024 \\
\hline
\end{tabular}

$*=\mathrm{P}<0.05$

$* *=0.05<\mathrm{P}<0.10$

Table 2. Table of Coefficients from Ordered Logistic Regression (OLR) Examining Effects of Pre-fire Tree Mortality, Slope, Aspect, Vegetation Type, Tree Size Class, and Canopy Cover Class on Fire Severity (Low, Moderate, Moderate/High) in Conifer Types within the October 2003 Old and Grand Prix Fires in the San Bernardino National Forest, California $(n=$ 415).

\begin{tabular}{|c|c|c|c|c|c|c|}
\hline Variable & Coeff. & SE & $\mathbf{z}$ & $\mathbf{P}>|\mathbf{z}|$ & \multicolumn{2}{|c|}{$95 \% \mathrm{CI}$} \\
\hline Insect/drought mortality & 0.020 & 0.032 & 0.63 & 0.532 & -0.043 & 0.083 \\
\hline Slope & 0.000 & 0.001 & -0.16 & 0.874 & -0.003 & 0.002 \\
\hline East & -0.191 & 0.240 & -0.80 & 0.425 & -0.662 & 0.279 \\
\hline South & -0.051 & 0.311 & -0.16 & 0.870 & -0.659 & 0.558 \\
\hline West $* *$ & -0.455 & 0.254 & -1.79 & 0.073 & -0.953 & 0.043 \\
\hline WHR size $5 * *$ & -0.343 & 0.206 & -1.67 & 0.095 & -0.746 & 0.060 \\
\hline WHR type MHC * & 0.915 & 0.244 & 3.75 & $<0.001$ & 0.437 & 1.394 \\
\hline WHR type SMC & -0.302 & 0.577 & -0.52 & 0.601 & -1.433 & 0.829 \\
\hline WHR density & 0.001 & 0.006 & 0.14 & 0.891 & -0.010 & 0.012 \\
\hline $\mathrm{XY} *$ & $5.8 \mathrm{E}-09$ & $1.9 \mathrm{E}-09$ & 3.03 & 0.002 & $2.1 \mathrm{E}-09$ & $9.6 \mathrm{E}-09$ \\
\hline Cutpoint 1 & -0.634 & 0.521 & & & & \\
\hline Cutpoint 2 & 1.109 & 0.524 & & & & \\
\hline
\end{tabular}

$*=\mathrm{P}<0.05$

$* *=0.05<\mathrm{P}<0.10$

aspect or those dominated by trees $28-60 \mathrm{~cm}$ dbh (Table 2). The pseudo $r^{2}$ value of 0.04 suggested that $4 \%$ of the variation in fire severity among locations was explained by our model.

\section{DISCUSSION}

We found that stands with recent high pre-fire tree mortality due to drought and insects did not burn at higher severity in coniferous forests of the San Bernardino Mountains, southern California, in the two fires we examined. Pollet and Omi [32] reported anecdotally that stands of lodgepole pine ( $P$. contorta) that experienced an insect epidemic in the 1940s in Yellowstone National Park burned at lower severities compared to adjacent burned areas in the 1994 Robinson Fire. A widespread low-severity fire in subalpine forests in the White River National Forest, Colorado did not burn any beetle-affected stands [13]. Further, Bebi et al. [12] found that stands of Engelmann spruce (Picea engelmannii) and subalpine fir (A. lasiocarpa) in the White River National Forest influenced by a spruce 
beetle outbreak in the 1940 s did not show higher susceptibility to 303 subsequent forest fires that burned after 1950. Our study area differed from these previous sites because most of the trees killed by insects and drought just prior to the fires in the San Bernardino Mountains were still standing and had retained needles. Despite differences in sites and forest types, previous studies and our results provide compelling evidence that when fire does occur, stands with considerable tree mortality due to drought and insects will not burn at higher severity than stands without significant tree mortality, either in the short or long term.

While pre-fire tree mortality had no effect on fire severity in burned stands, we found that sample locations dominated by the largest size class of trees $(\geq 61 \mathrm{~cm} \mathrm{dbh})$ burned at lower severities than locations dominated by trees $28-60 \mathrm{~cm}$ dbh (Table 2). This result suggests that harvesting largersized trees for fire-severity reduction purposes is likely to be ineffective, and possibly counter-productive. These findings corroborate other recently published studies indicating that retention of the largest trees is likely to maintain normative fire behavior [33-35]. The smallest tree-size classes were not included in our analyses due to low sample sizes, so we could not determine the effects of still smaller tree-size classes on fire severity. An additional limitation on the potential effectiveness of fuel treatments to reduce fire severity in stands with high pre-fire mortality is the low likelihood that such stands will be affected by fire [14].

Weather conditions can supersede the influence of stand structure and fuels on fire behavior in mixed-severity fire regimes [36], which probably accounts for the low $\mathrm{r}^{2}$ values of our models. We included topographical and stand structure variables, but we had no variables for wind speed, air temperature, and fuel and air moisture levels, for example. Odion and Hanson [36] analyzed the spatial patterns of fire severity for conifer forests in the three largest fires in the Sierra Nevada Mountains, California since 2000, and found that high-severity fire ranged from 10.9 to $28.9 \%$ of total area burned. Overall, we documented that $32 \%$ of conifer and mixed hardwood-conifer types burned at moderate/high severity in the 2003 Old and Grand Prix fires. The Old and Grand Prix fires may have had relatively high proportions of moderate/high severity due to the extreme fire weather resulting from Santa Ana winds, the lack of largetree components due to past harvest, or some combination thereof.

\section{ACKNOWLEDGEMENTS}

We thank the USDA Forest Service, San Bernardino National Forest, and the US Geological Survey for providing us with their GIS data layers, and two anonymous reviewers for helpful comments. We are grateful to Environment Now for funding this research.

\section{REFERENCES}

[1] Black SH. Logging to control insects: The science and myths behind managing forest insect "pests." A synthesis of independently reviewed research. The Xerces Society for Invertebrate Conservation. Portland: 2005 [cited 2009 April 9]. Available from: http://www.xerces.org/guidelines-logging-tocontrol-insects/
[2] Maloney PE, Rizzo DM. Pathogens and insects in a pristine forest ecosystem: the Sierra San Pedro Martir, Baja, Mexico. Can J For Res 2002; 32: 448-57.

[3] Breshears DD, Cobb NS, Rich PM, et al. Regional vegetation dieoff in response to global- change-type drought. Proc Nat Acad Sci USA 2005; 102: 15144-8.

[4] Miller JM, Keen FP. Biology and control of the western pine beetle: A summary of the first fifty years of research. Miscellaneous Publication 800. Washington: USDA Forest Service Southwest Forest Range Experimental Station; 1960.

[5] Bradley T, Tueller P. Effects of fire on bark beetle presence on Jeffrey pine in the Lake Tahoe Basin. For Ecol Manage 2001; 142: 205-14.

[6] Wallin K, Kolb T, Skov K, et al. Seven-year results of thinning and burning restoration treatments on old ponderosa pines at the Gus Pearson natural area. Restor Ecol 2004; 12: 239-47.

[7] Sala A, Peters G, McIntyre L, et al. Physiological responses of ponderosa pine in western Montana to thinning, prescribed fire and burning season. Tree Physiol 2005; 25: 339-48.

[8] Sanchez-Martinez G, Wagner MR. Bark beetle community structure under four ponderosa pine stand conditions in northern Arizona. For Ecol Manage 2002; 170: 145-60.

[9] Schwilk DW, Knapp EE, Ferrenberg SM, et al. Tree mortality from fire and bark beetles following early and late season prescribed fires in a Sierra Nevada mixed-conifer forest. For Ecol Manage 2006; 232: 36-45.

[10] Furniss RL, Carolin VM. Western forest insects. Miscellaneous Publication 1339. USDA Forest Service; 1977.

[11] Stuart JD, Agee JK, Gara RL. Lodgepole pine regeneration in an old, self-perpetuating forest in south central Oregon. Can J For Res 1989; 19: 1096-1104.

[12] Bebi P, Kulakowski D, Veblen TT. Interactions between fire and spruce beetles in a subalpine Rocky Mountain Forest landscape. Ecology 2003; 84: 362-71.

[13] Kulakowski D, Veblen TT, Bebi P. Effects of fire and spruce beetle outbreak legacies on the disturbance regime of a subalpine forest in Colorado. J Biogeogr 2003; 30: 1445-56.

[14] Rhodes JJ, Baker WL. Fire probability, fuel treatment effectiveness and ecological tradeoffs in western U.S. public forests. Open Forest Sci J 2008; 1: 1-7.

[15] Keeley JE, Fotheringham CJ. Lessons learned from the wildfires. In: Halsey RW, Ed. Fire, Chaparral, and Survival in Southern California. San Diego: Sunbelt Publications, Inc. 2005; 112- 122.

[16] Agee JK. Fire Ecology of Pacific Northwest Forests. Washington: Island Press 1993.

[17] Kauffman JB. Ecological relationships of vegetation and fire in Pacific Northwest forests. In: Walstead JD, Radosevich SR, Sandberg DV, Eds. Natural and Prescribed Fire in Pacific Northwest Forests. Corvallis: Oregon State University Press 1990; pp. 39-52.

[18] Sawyer JO, Thornburgh DA, Griffin JR. Mixed evergreen forest. In: Barbour MG, Major J, Eds. Terrestrial vegetation of California. $2^{\text {nd }}$ ed. Sacramento: California Native Plant Society 1988; pp. 359382 .

[19] Thorne RF. Montane and subalpine forests of the Transverse and Peninsular Ranges. In: Barbour MG, Major J. Eds. Terrestrial vegetation of California. $2^{\text {nd }}$ ed. Sacramento: California Native Plant Society 1988; pp. 537-558.

[20] Barbour MG, Minnich RA. California upland forests and woodlands. In: Barbour MG, Billings WD, Eds. North American Terrestrial Vegetation. New York: Cambridge University Press 2000; pp. 161-202.

[21] Stephenson JR, Calcarone GM. Southern California mountains and foothills assessment: habitat and species conservation issues. PSWGTR-172. Albany, CA: USDA Forest Service Pacific Southwest Research Station 1999.

[22] U.S. Department of Agriculture Forest Service. 2005. FSSDE.EvegTile52_02_03 and EvegTile54_03: [cited 2006 Aug 1]. Available from: http://www.fs.fed.us/r5/rsl/clearinghouse/data. shtml

[23] U.S. Department of Agriculture Forest Service. 2005. bdf_mort05_ir: [cited 2005 July 21]. Available from: http://www.f.fs.fed.us/r5/rsl/projects/frdb/layers/mort.html

[24] U.S. Department of Interior Geological Survey. 2006. 2003old_b_class.tif and 2003grndprix_b_class.tif: [cited 2006 Feb 21]. Available from: http://edc.usgs.gov 
[25] U.S. Department of Interior Geological Survey. 2006. 1-Arc Second National Elevation Dataset: [cited 2006 Feb 21]. Available from: http://seamless.usgs.gov

[26] Mayer KE, Laudenslayer WF. California Wildlife Habitat Relationship Habitat Type. California Department of Fish and Game, 2002.

[27] Miller JD, Thode AE. Quantifying burn severity in a heterogeneous landscape with a relative version of the delta Normalized Burn Ration (dNBR). Remote Sensing Environ 2007; 109: 66-80.

[28] Thode AE. Quantifying the fire regime attributes of severity and spatial complexity using field and imagery data. Ph.D. Dissertation. Davis: University of California 2005.

[29] Stephens SL, Finney MA. Prescribed fire mortality of Sierra Nevada mixed conifer tree species: effects of crown damage and forest floor combustion. For Ecol Manage 2002; 162: 261-71.

[30] Legendre P. Spatial autocorrelation: trouble or new paradigm? Ecology 1993; 74: 1659-73.
[31] Legendre P, Legendre L. Numerical ecology. Amsterdam: Elsevier Science 1998.

[32] Pollet J, Omi PN. Effect of thinning and prescribed burning on crown fire severity in ponderosa pine forests. Int J Wildl Fire 2002; 11: $1-10$

[33] Omi PN, Martinson EJ. Effects of fuels treatment on wildfire severity. Final report. Joint Fire Science Program Governing Board, Western Forest Fire Research Center. Fort Collins: Colorado State University 2002.

[34] Perry DA, Jing H, Youngblood A, et al. Forest structure and fire susceptibility in volcanic landscapes of the Eastern High Cascades, Oregon. Conserv Biol 2004; 18: 913-26.

[35] Stephens SL, Moghaddas JJ. Silvicultural and reserve impacts on potential fire behavior and forest conservation: Twenty-five years of experience from Sierra Nevada mixed conifer forests. Biol Conserv 2005; $125: 369-79$

[36] Odion DC, Hanson CT. Fire severity in conifer forests of the Sierra Nevada, California. Ecosystems 2006; 9: 1177-89.

(C) Bond et al.; Licensee Bentham Open.

This is an open access article licensed under the terms of the Creative Commons Attribution Non-Commercial License (http://creativecommons.org/licenses/bync/3.0/) which permits unrestricted, non-commercial use, distribution and reproduction in any medium, provided the work is properly cited. 